Racism and Society 


\section{SOCIOLOGY FOR A CHANGING WORLD}

Series Editors: Graham Allan and Mary Maynard

Consultant Editor: Janet Finch

This series, published in conjunction with the British Sociological Association, evaluates and reflects major developments in contemporary sociology. The books will focus on key changes in social and economic life in recent years and on the ways in which the discipline of sociology has analysed those changes. The books will reflect the state of the art in contemporary British sociology, while at the same time drawing upon comparative material to set debates in an international perspective.

\section{Published}

Graham Allan and Graham Crow, Families, Households and Society

Rosamund Billington, Annette Fitzsimmons, Lenore Greensides

and Sheelagh Strawbridge, Culture and Society

Lois Bryson, Welfare and the State: Who Benefits?

Frances Heidensohn, Crime and Society

Stephen J. Hunt, Religion in Western Society

Mike Savage and Alan Warde, Urban Sociology, Capitalism and Modernity

John Solomos and Les Back, Racism and Society

Philip Sutton, Nature, Environment and Society

Andrew Webster, Science, Technology and Society

Forthcoming

Kevin Brehony and Rosemary Deem, Rethinking Sociologies of Education

Gordon Causer and Ray Norman, Work and Employment in Contemporary Society

Jörg Dürrschmidt and Graham Taylor, Globalisation, Modernity and Social Change

David Morgan, Men, Masculinites and Society

Julie Seymour, Social Research Methodology

\section{Series Standing Order}

If you would like to receive future titles in this series as they are published, you can make use of our standing order facility. To place a standing order please contact your bookseller or, in case of difficulty, write to us at the address below with your name and address and the name of the series. Please state with which title you wish to begin your standing order. (If you live outside the United Kingdom we may not have the rights for your area, in which case we will forward your order to the publisher concerned.)

Customer Services Department, Macmillan Distribution Ltd Houndmills, Basingstoke, Hampshire RG21 6XS, England 


\title{
RACISM AND SOCIETY
}

\author{
John Solomos
}

and

Les Back 


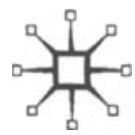

(C) John Solomos and Les Back 1996

All rights reserved. No reproduction, copy or transmission of this publication may be made without written permission.

No paragraph of this publication may be reproduced, copied or transmitted save with written permission or in accordance with the provisions of the Copyright, Designs and Patents Act 1988, or under the terms of any licence permitting limited copying issued by the Copyright Licensing Agency, 90 Tottenham Court Road, London W1T 4LP.

Any person who does any unauthorised act in relation to this publication may be liable to criminal prosecution and civil claims for damages.

The authors have asserted their rights to be identified as the authors of this work in accordance with the Copyright, Designs and Patents Act 1988.

Published by PALGRAVE MACMILLAN

Houndmills, Basingstoke, Hampshire RG21 6XS and

175 Fifth Avenue, New York, N. Y. 10010

Companies and representatives throughout the world

PALGRAVE MACMILLAN is the global academic imprint of the Palgrave Macmillan division of St. Martin's Press, LLC and of Palgrave Macmillan Ltd. Macmillan ${ }^{\otimes}$ is a registered trademark in the United States, United Kingdom and other countries. Palgrave is a registered trademark in the European Union and other countries.

ISBN 978-0-333-58439-2

ISBN 978-1-349-24735-6 (eBook)

DOI 10.1007/978-1-349-24735-6

This book is printed on paper suitable for recycling and made from fully managed and sustained forest sources.

A catalogue record for this book is available from the British Library.

Transferred to digital printing 2002 
For Kyriacou Solomou, Nikolas Solomou, Joan Back and Bob Back with much love, for the support they have provided over the years 


\section{Contents}

List of Figures

ix

Acknowledgements $\quad \mathrm{x}$

Preface

1 Theoretical Perspectives 1

Race and sociological theory 3

Neo-Marxism and racism $\quad 7$

Feminism, race and ethnicity 11

New ethnicity, new racism 16

Racism and 'whiteness' 22

Conceptualising racisms and racial discourse $\quad 25$

2 Historical Perspectives $\quad 30$

Changing ideas about race $\quad 31$

Racism, slavery and capitalism $\quad 37$

Race, science and society $\quad 42$

Imperialism, colonialism and race $\quad 45$

Anti-Semitism, Nazism and the racial state $\quad 49$

Migrant labour, race and society $\quad 53$

Racism in comparative perspective $\quad 56$

3 Social Relations and Racial Inequality $\quad 60$

Racism and social relations $\quad 61$

Racialisation and exclusionary practices $\quad 66$

Racism, integration and the liberal agenda $\quad 72$

Racial inequalities and social change 76

4 Racism, Class and Political Action 79

Race, politics and society $\quad 81$

$\begin{array}{ll}\text { Racism and political action } & 84\end{array}$

Racism, class and exclusion $\quad 88$ 
viii Contents

Race, community and resistance $\quad 94$

Dynamics of racial formation 97

5 Racism and Anti-Racism 102

Conceptualising anti-racism 103

The politics of anti-racism 110

Anti-racist movements 111

Multiculturalism and anti-racism 113

Anti-racist policies and practices $\quad 116$

What kind of anti-racism? 117

6 Identity, Hybridity and New Ethnicities 121

Anthropology in the metropolis: ethnic identity and models of ethnicity 122

Ethnicity and identity 128

Identification, hybridity and new ethnicities 132

Blackness and the end of innocence 134

Diaspora, hybridity and belonging 141

Syncretic fascism? Transnationality and racist culture 145

Cultural politics and difference 153

7 Race, Racism and Popular Culture 156

Icons of nationhood: John Bull, Britannia and empire 158

Nazism, propaganda and visual culture 167

Racism and representing the black presence in Britain 179

Corporate multiculturalism: racism, difference and media images 185

$\begin{array}{ll}\text { Popular culture and difference } & 198\end{array}$

8 Shifting Meanings of Race and Racism 202

Constructions of race 205

New forms of racism $\quad 212$

Citizenship, multiculturalism and anti-racism 214

Prospects for the future 216

Guide to Further Reading 221

References 224

$\begin{array}{ll}\text { Index } & 247\end{array}$ 


\section{List of Figures}

7.1 Britannia and the domestic: Vinolia toothpaste advert, 1915

7.2 John Bull as an English champion: England's Glory Matches tin sign, 1905

7.3 Nazi cartoon representations of the black Allied soldier

7.4 'Greetings from England: The Coming Invasion'. Nazi pamphlet circulated in Holland, 1944

7.5 Monstrous Regiment: Nazi poster portraying the GI as a jitterbugging marauder. Poster in Holland, 1944

7.6 United Colors? Benetton billboard poster, 1991

7.7 Altered Image: Toscani's portrait of a black Queen Elizabeth, spring 1993 


\section{Acknowledgements}

The author and publisher wish to thank the following who have kindly given permission for the use of copyright material:

The Robert Opie Collection, for Britannia and the domestic: Vinolia advertisement, 1915 (p. 162);

The Robert Opie Collection, for John Bull as an English champion: England's Glory Matches tin sign, 1905 (p. 165);

A Rhodes Propaganda: The Art of Persuasion in World War II Angus Robertson, for a Nazi cartoon representing the black Allied soldier (p. 173);

'Greetings from England: The Coming Invasion' Nazi pamphlet circulated in Holland, 1944 (p. 175);

Monstrous Regiment: Nazi poster portraying the GI as a jitterbugging marauder: Poster in Holland, 1944 (p. 177);

Benetton Publicity, for United Colors? Benetton billboard poster, 1991 (p. 188);

Benetton Publicity courtesy of Colors Magazine, for Altered Image: Toscani's portrait of a black Queen Elizabeth, spring 1993 (p. 198).

Every effort has been made to trace all the copyright-holders but if any have been inadvertently overlooked the publisher will be pleased to make the necessary arrangements at the first opportunity. 


\section{Preface}

It is impossible in the present environment to ignore the role of ideas about race in shaping and determining the social and political relations of societies all over the globe. Whether one looks at the popular media or at the changing research agendas of the social sciences and humanities, there is no escaping the realisation that questions about race and related social issues are at the heart of a whole range of debates. If we take the situation in Britain and other European societies as a case in point, there seems little doubt that immigration and race relations have come to occupy an important space in political debates about many aspects of social and economic policy (Balibar and Wallerstein, 1991; Miles, 1993; Wrench and Solomos, 1993). As a number of commentators have noted an underlying theme in American debates about a whole range of social issues is the question of race. Studs Terkel, a perceptive commentator on American culture and society, captures a key aspect of contemporary trends when he talks of the 'obsession' with race in all sectors of urban America (Terkel, 1992).

A good example of this process is the debate that has taken place in numerous advanced industrial societies about the issue of the underclass. Although it is clear that this subject cannot be seen easily through a racial lens in all national and localised social and economic environments, there is a clear racial theme in much of the policy debate about both the causes and the solutions to this phenomenon (Smith, 1992; Weir, 1993). Another instance of the increasing salience of race can be found in the wave of political mobilisations about immigration, national identity and related issues across Europe during the 1990s. These have served above all else to highlight the importance of racism as a social and political force. But these new forms of mobilisation have also raised important questions about what it is exactly that we mean when we refer to racism in contemporary societies, and how we con- 
ceptualise the differences and similarities between the present and the past. Over the past few years there has been much journalistic writing and speculation about these topics, but as yet there has been little systematic analysis of the underlying historical and conceptual issues.

It is partly as a result of such developments that we have seen an unprecedented explosion of academic interest in the study of race and racism as social, cultural and political phenomena. Without too much exaggeration one can say that the study of the history and contemporary expressions of racism has come to the fore in a wide range of academic disciplines. Whilst perhaps even a decade ago the study of racism was a highly specialised field in such disciplines as history, sociology and politics, there is a hardly any branch of the social sciences and humanities which has not witnessed a resurgence of interest in the study of various aspects of racism. This is reflected in the wide range of monographs and edited collections about race and racism that have come out over the past few years, as well as in the changing research agenda in universities and research institutes. Indeed, it is clear that questions about race, ethnicity and identity have come to occupy a key role within contemporary debates about postmodernism and globalisation (Kristeva, 1991; Hall, 1992; Kristeva, 1993; Rattansi and Westwood, 1994; Winant, 1994).

It is against this background that we began work on Racism and Society, and in this sense it is a book of its time. It is a contribution to the ongoing discussion of the role of race and ethnicity in contemporary societies. But it is also worth emphasising that is also the result of our long-standing concern with the analysis of the role and changing contours of racial ideologies and practices in contemporary societies. We have worked on various aspects of this question for over a decade and felt it appropriate to try to provide an overview of what we see as some of the key issues and main trends in this field of social analysis. Additionally, we felt unhappy with the ways in which existing texts dealt with the complex range of issues raised by the study of race and racism in contemporary societies. In this sense this volume is an attempt to outline the broad contours of the study of the role that race and racism play in shaping social relations and institutions, and to encourage further debate and analysis. We do not see this book as a text that provides the final word on this subject. Indeed, what 
makes the study of contemporary forms of race and racism such an interesting and challenging area at the present time is the complex range of social and political relations researchers have sought to explore and the variety of theoretical perspectives that have been developed to provide the conceptual tools for this research. What we seek to provide, therefore, is a critical overview of some of the key issues as we see them.

Given recent developments in Europe, the United States and elsewhere, we hardly need reminding that the boundaries of the study of the relationship between racism and society are by no means fixed and unchanging. Indeed, in writing this volume we became even more aware than we were at the beginning of our endeavours of the complexity of the issues we were attempting to analyse and of the need to utilise perspectives from a range of theoretical and historical research in order to provide a useful and critical intervention in current debates. This has become particularly clear in the context of recent developments in both Western and Eastern Europe, where in quite diverse social and political contexts we have seen the emergence of new forms of racism and ethnic nationalism that have had a devastating impact at both a personal and a collective level (Zižek, 1993). It is also clear that in contemporary societies ideas about the social relevance of race are by no means uniform and unchanging. Hence the tendency of many commentators to use notions such as new racism and cultural racism in order to talk about the changing morphology of racial ideas and practices in societies such as Britain, the United States of America and other Western societies.

The changing meaning and social role of race and racism in the present social and political environment makes it inherently difficult to provide a comprehensive account of this field of study. Yet this is what we are attempting to do, with the clear understanding that our account of key issues and processes is both provisional and limited in its objectives. Rather than retracing familiar theoretical and historical territory the main concerns of the book will be to concentrate on how sociologists and other social researchers have attempted to provide conceptual frameworks for the analysis of racialised social relations and how they have applied these frameworks to the analysis of specific social phenomena. We hope that in exploring the interplay between theory and historical analysis we can see how far we have moved 
towards a better understanding of the ways in which race is used in particular social and historical contexts, what it signifies and its impact on social, political, economic and cultural processes in contemporary societies.

Rather than focus on the rather narrow issue of whether or not race is a social scientific category as such, we shall explore the ways in which it becomes a form of collective social identity in particular social and historical circumstances. It should be clear from the tenor of the arguments to be found in this volume that we do not see race as a natural category in any sense, though it is often used as such. Race and ethnic categories are ideological entities that are made and remade through struggle. In this sense race can be seen as a discursive category through which differences are accorded social significance. But it is also more than just a discursive category since it carries with it material consequences for those who are included within, or excluded from, a particular racial identity.

We hope also to show the value of dialogue between researchers who are working within a variety of disciplines and theoretical perspectives. What we shall suggest is that it is necessary to evaluate radically the contribution of all the main paradigms in this field. While it may be beyond the scope of a single volume to attempt to discuss all of the important theoretical and historical contributions that we have seen in this field over the past few decades, we have attempted to provide a sharply focused overview of these debates that ranges across narrow disciplinary boundaries. This is partly because we have seen in recent years an explosion of interest in the study of race and racism from within a variety of disciplines. There have been important contributions from sociology, politics, geography, cultural studies and literary theory, psychology and related fields. This growth of interest in the study of race and racism has led to an expansion of the research agenda to take account of key aspects of racialised relations in contemporary societies. Quite apart from the traditional focus on studies of communities and institutions, we have seen a growing number of studies that look at issues such as political mobilisation, policing and socio-legal processes, youth, popular culture, race and gender, sexuality and the history of racial ideas. Additionally, we have seen important political debates about the role of policy change and state policies in this field, including the 
role of initiatives that are predicated on the construction of multicultural and anti-racist strategies for dealing with the role of racist ideologies and racial discrimination.

Our main aim in writing this book is to examine two key dimensions of contemporary racial relations. The first may be broadly seen as covering the social and political aspects of the analysis of race and racism in contemporary societies. The analysis in this part of the book is intended to provide the basis of a theoretical and conceptual framework for analysing contemporary forms of racism and the social relations that arise on the basis of racial categorisation. The second dimension is an exploration of how ideas about race mobilise social and cultural processes that help shape our understandings of what racial relations are in contemporary societies. This means, above all, that we are concerned to show how and why in particular contexts social and cultural discourses about race and ethnicity converge and help to shape policies and practices around specific social groups and 'problems'. In this part of the book we shall also explore the variety of ways in which racialised minorities themselves have mobilised notions of race, ethnicity and culture in organising themselves both socially and politically.

These concerns explain the way in which the various chapters are organised. The first two concentrate on the analysis of the theoretical and historical context of the study of race and racism as aspects of contemporary social relations. Taken together they are intended as a brief, and critical, analysis of research and scholarship about race and racism in contemporary societies. In Chapter 1 we consider the changing terms of theoretical debates concerning the ways in which the social category of race is used and what it is supposed to signify. This involves an exploration of the changing terms of debate about the role of the processes through which the category of race is attributed social significance, and their consequences for social structures and institutions. Chapter 2 then takes the analysis further by looking at some of the key historical aspects of the uses of race in specific contexts and their impact on the emergence and significance of ideas about race in contemporary societies. This is an area of much heated debate over the years and we provide a critical account of the main perspectives that have resulted from research on the history of racial ideas and of their impact on specific social contexts. 
The main concern of the first two chapters can be seen as laying the foundations for the analysis to be found in the rest of the book. Chapter 3 extends this account by exploring the question of racial inequalities and how they have been analysed. We look specifically at the interface between racialised inequalities and inequalities deriving from class, gender and wider sets of social relations. This is followed in Chapter 4 by an analysis of the relationship between race and forms of political action, focusing on the complex ways in which ideas about race have influenced and continue to influence political institutions and the channels through which both majorities and minorities mobilise politically. Chapter 5 then deals with the continuing debate about the nature of racism and anti-racism. This is a thorny problem, as the range of interventions in recent years about the question of what some writers call 'new racism' shows.

In Chapters 6 and 7 we shift focus somewhat and look at the ethnic and cultural dimension of contemporary racial relations. Chapter 6 takes up the question of the relation between race, culture and ethnicity in shaping what one might term the cultural forms of mobilisation around these signifiers. This requires a critical analysis of the increasingly complex and ambivalent forms of racialised identities which are to be found in contemporary societies and the ways they are understood and analysed. We seek to go beyond the limits of recent debates by exploring the changing expressions of ethnic and cultural identity in the present sociopolitical environment. In Chapter 7 there follows the analysis of the role played by race and racism in constructions of popular cultural forms. This is an arena which has been much discussed in recent years, particularly in relation to the renewed interest in the study of the role that culture plays in shaping our understandings of race and ethnicity in the modern environment. What recent debates have tended to do, however, is to look at these processes from a largely ahistorical perspective. In order to remedy this gap we have attempted to situate more recent developments within a broader historical account. This is most evident in our depiction of race and popular culture in British society and in the discussion of the role of racial symbols in Nazi popular culture.

Finally, in Chapter 8 we consider the consequences of the shifting meanings of race and racism in the present socio-political environment. This allows us to return to some of the thorny the- 
oretical questions that we touched on in the first part of the book. In particular we take up the suggestion made by some writers that we need to develop a conception of racism that takes as its starting point the existence of complex and multifarious racisms in specific historical contexts. Additionally, we take an exploratory look at some of the issues that are likely to confront us in the coming period in thinking through the question of what can be done to tackle the rise of racism in its various forms, with its consequent costs for humanity.

Over the years we have been aided in exploring and analysing these questions by colleagues and friends. We were able to present some of our arguments to the varied and friendly groups of people that regularly attended the Workshop on the Politics of Racism at Birkbeck College from 1988 to 1993 . We would like in particular to express our gratitude for the help and encouragement of Clive Harris and Michael Keith, who kindly commented on aspects of the argument as it developed. We hope that they agree that we listened to at least some of their comments. Parminder Bhachu provided us with kind words of encouragement from a distance, which were much appreciated. Our respective academic institutions provided the space and environment for us to work on this volume, at a time of increasing pressure on academic research time. For that we are grateful. Paul Moody was kind enough to provide us with some of the illustrations we have used in Chapter 7. Our publishers, Frances Arnold and Catherine Gray, provided the right balance between critical suggestions and encouragement to keep us going and made sure that we did not forget the nature of our audience. The editors of this series, Graham Allan and Mary Maynard, provided valuable comments which were of great assistance during the revision of a number of chapters. The Baggies offered a very different but no less important source of inspiration, sustenance and exasperation, while that intoxicating victory over the Wolves in March 1995 came at a particularly important point during completion of the final version, and helped us along. Further encouragement was provided by the Economic and Social Research Council which funded our joint research on Race, Politics and Social Change in Birmingham (Award No. R000231545). This. funding has resulted in a study of contemporary forms of racialised politics and social change, in which we attempted 
among other things to provide an analysis of new forms of political mobilisation and the changing terms of discourses about race in the present environment (Solomos and Back, 1995).

It was while working on this study that we also became conscious of the need to explore some of the conceptual and theoretical issues arising from our writing and discussions in more detail. Another source of inspiration in producing this volume came from our own students. They helped to make us conscious of the need for a critical text that explores the changing dynamics of the relationship between racism and social relations in the contemporary global environment. Although in recent years there has been a flood of edited collections and monographs on key features of contemporary racism many of these texts have looked at only some of the theoretical debates, particularly those arising from the engagement with postmodernism and cultural studies. It seems to us that there is at the present time a clear need for a text that engages with these recent debates but at the same time provides a rounded, accessible and historically informed account of the interrelationship between racism and social relations. This book is our attempt to produce such a text, though it represents very much work in progress. We hope that all the above, in their different ways, find our endeavours of interest, though we take final responsibility for the product.

JOHN SOLOMOS

LES BACK 